\title{
Impaired insulin secretion in vivo but enhanced insulin secretion from isolated islets in pancreatic beta cell-specific vascular endothelial growth factor-A knock-out mice
}

\author{
N. Iwashita $\cdot$ T. Uchida $\cdot$ J. B. Choi $\cdot$ K. Azuma $\cdot$ \\ T. Ogihara $\cdot$ N. Ferrara $\cdot$ H. Gerber $\cdot$ R. Kawamori • \\ M. Inoue $\cdot$ H. Watada
}

Received: 21 June 2006 / Accepted: 22 September 2006 / Published online: 16 December 2006

(C) Springer-Verlag 2006

\begin{abstract}
Aims/hypothesis Endothelial cells are considered to be essential for normal pancreatic beta cell function. However, there have been no reports showing their importance for beta cell function.

Materials and methods Using mice with disrupted vascular endothelial growth factor-A gene specifically in beta cells, we investigated the relation between islet vascular structure and beta cell function.

Results Mice with disrupted vascular endothelial growth factor-A gene specifically in beta cells had reduced islet vascular density with impaired formation of endothelial fenestration. While their fasting glucose and body weight were comparable with control mice, their glucose- and
\end{abstract}

Electronic supplementary material Supplementary material is available in the online version of this article at http://dx.doi.org/ $10.1007 / \mathrm{s} 00125-006-0512-0$ and is accessible to authorised users.

N. Iwashita $\cdot$ T. Uchida J. B. Choi $\cdot$ K. Azuma $\cdot$ T. Ogihara

R. Kawamori $\cdot$ H. Watada $(\bowtie)$

Department of Medicine, Metabolism and Endocrinology,

Juntendo University School of Medicine,

2-1-1 Hongo, Bunkyo-ku,

Tokyo 113-8421, Japan

e-mail: hwatada@med.juntendo.ac.jp

N. Ferrara $\cdot$ H. Gerber

Department of Molecular Oncology, Genentech Inc.,

South San Francisco, CA, USA

M. Inoue $(\square)$

Department of Biochemistry,

Osaka Medical Center for Cancer and Cardiovascular Disease,

1-3-3 Nakamichi, Higashi-ku,

Osaka 537-8511, Japan

e-mail: inoue-ma2@mc.pref.osaka.jp tolbutamide-induced rapid insulin release were impaired, thus resulting in glucose intolerance. On the other hand, glucose and $\mathrm{KCl}$ enhanced the levels of insulin secreted from islets isolated from these mice. In addition, the production of soluble $\mathrm{N}$-ethylmaleimide-sensitive factor attachment protein receptors in the islets was increased. Insulin content and expression of insulin I and pancreas duodenum homeobox $1 \mathrm{mRNA}$ in the islets were also increased.

Conclusions/interpretation Our results indicate that an abnormal quality and quantity of blood vessels due to reduced expression of vascular endothelial growth factor-A in beta cells could be a cause of impaired insulin secretion without impairment of beta cell function.

Keywords Endothelial cells · Islet · Microvasculature · VEGFA

\begin{tabular}{|c|c|}
\hline \multicolumn{2}{|c|}{ Abbreviations } \\
\hline CRE & cyclisation recombination \\
\hline Ins1 & insulin I \\
\hline KRS & Krebs-Ringer solution \\
\hline PDX1 & pancreas duodenum homeobox 1 \\
\hline PDX1-CRE & $\begin{array}{l}\text { mice in which CRE recombinase is } \\
\text { under transcriptional control of PDX } 1\end{array}$ \\
\hline RIP & rat insulin promoter \\
\hline RIP-CRE & $\begin{array}{l}\text { mice in which CRE recombinase is } \\
\text { under transcriptional control of the } \\
\text { rat insulin promoter }\end{array}$ \\
\hline SNARE & $\begin{array}{l}\text { soluble } N \text {-ethylmaleimide-sensitive factor } \\
\text { attachment protein receptors }\end{array}$ \\
\hline $\mathrm{VEGF}^{\mathrm{fl} / \mathrm{fl}}$ & $\operatorname{VEGF}^{\mathrm{fl} / \mathrm{fl}}\left(\mathrm{CRE}^{-}\right)$, VEGFA/loxP mouse line \\
\hline VEGF & vascular endothelial growth factor \\
\hline VEGFR & VEGF receptor \\
\hline
\end{tabular}




\section{Introduction}

Insulin is secreted from pancreatic islets by various physiological secretagogues and an adequate and precise pattern of insulin secretion is essential to maintain normal blood glucose levels. To achieve normal dynamics of blood insulin levels, both the beta cells and vascular system in islets may play important roles [1]. The islet capillary network is about five times denser than that of the exocrine tissue and the microvasculature of pancreatic islets consists of thin fenestrated endothelial cells separated from beta cells by the basement membrane $[1,2]$. The islet microvasculature has a unique relationship with beta cells, which are polarised with one domain facing an arterial capillary and another facing a venous capillary [3]. In addition, islets contain canaliculi located between the lateral faces of beta cells. These canaliculi contain many microvilli with high production of GLUT2 (now known as solute carrier family 2 [facilitated glucose transporter], member 2) [4]. These vascular networks might contribute to the rapid sensing of blood glucose in beta cells and the rapid trans-endothelial passage of insulin follows highly regulated exocytosis of insulin-containing granules. However, both the role of the islet vascular system as such in physiological glucose tolerance in vivo, and its impact remain elusive.

In the pancreas, vascular endothelial growth factor (VEGF)-A is highly produced in islets compared with exocrine cells $[5,6]$. VEGF is a key regulator of vasculogenesis, angiogenesis, vascular permeability, and endothelial fenestration formation [7-9]. As demonstrated previously, beta cell-specific deletion of Vegfa (seen in mice in which cyclisation recombination [CRE] recombinase is under transcriptional control of the rat insulin promoter [RIP; RIP-CRE], in combination with a VEGF-A/ loxP mouse line $\left[\mathrm{VEGF}^{\mathrm{f} / \mathrm{fl}}\right]$, where exon 3 of the VEGFA gene is flanked by loxP recombination sites [floxed], [RIP$\left.\mathrm{CRE}: \mathrm{VEGF}^{\mathrm{fl} / \mathrm{fl}}\right]$ ) results in reduced vascularisation in islets [6]. In addition, pancreatic-specific deletion of Vegfa (seen in mice in which CRE recombinase is under transcriptional control of the pancreas duodenum homeobox1 [PDX1; PDX1-CRE], in combination with a VEGF ${ }^{\mathrm{fl} / \mathrm{fl}}$; PDX1-CRE: $\mathrm{VEGF}^{\mathrm{fl} / \mathrm{fl}}$ ) also results in reduced vascularisation and fenestration of islet capillaries [10]. Although other family members of VEGF are expressed in beta cells [6], these results clearly indicate that VEGFA in the pancreas plays a nonredundant role in the formation of dense fenestrated capillaries in islets.

VEGFA binds to VEGF receptor (VEGFR)-1 (also known as FMS-like tyrosine kinase 1 [FLT1]) and VEGFR-2 (also know as kinase insert domain protein receptor [KDR]), the production of which is largely restricted to endothelial cells. On the other hand, other family members also bind to VEGFR-1 and VEGFR-2. Thus placental growth factor and VEGFB can bind to VEGFR-1, while VEGFC and VEGFD can bind to VEGFR-2 [11]. A recent study investigated the effect of AG013736, which inhibits VEGF receptor tyrosine kinases, including VEGFR-1, VEGFR-2, soluble VEGFR-1 (which inhibits the ligand binding to VEGFR-1) and soluble VEGFR-2 (which inhibits the ligand binding to VEGFR-2), on microvasulature in several tissues [5]. The investigators demonstrated that administration of AG-013736 results in a $60 \%$ decrease in intra-islet microvasculature, that soluble VEGFR-1 results in a 54\% decrease in intra-islet microvasculature, and that soluble VEGFR-2 results in a 14\% decrease in intra-islet vasculature. These findings suggest that VEGFA plays an important role in intra-islet vascular structure through binding to VEGFR-1, although other factors could partly substitute the effect of VEGFA.

PDX1-CRE:VEGF ${ }^{\mathrm{fl} / \mathrm{fl}}$ mice show glucose intolerance with a reduced number of insulin-containing granules in their islets $[10,12]$. However, it is not clear whether the impaired glucose tolerance in this model is caused by a defect in beta cells or in the vascular system. In addition, pancreatic organogenesis is highly regulated by blood vessels as a source of developmental signals [13]. While the apparent morphological defect has not been reported in this model, the effect of Vegfa deletion in the early developmental stage might be important. Thus, in this study, we used mice with beta-cell-specific deletion of Vegfa to elucidate the functional role of the islet microvascular system.

\section{Materials and methods}

Animals The study protocol was reviewed and approved by the Animal Care and Use Committee of Juntendo University, School of Medicine and Osaka Medical Center for Cancer and Cardiovascular Disease (both Japan). All mice were housed in specific pathogen-free barrier facilities, with a 12-h light-dark cycle, and free access to standard rodent food (Oriental Yeast, Osaka, Japan) and water.

In this study, the bacteriophage CRE/loxP-specific recombination system was used to generate a beta-cellspecific Vegfa-null allele. The generation and characterisation of RIP-CRE transgenic mice [14], and $\mathrm{VEGF}^{\mathrm{fl} / \mathrm{fl}}$ $\left(=\mathrm{VEGF}^{\mathrm{fl} / \mathrm{fl}}\left[\mathrm{CRE}^{-}\right]\right)$mice [15] has been reported previously. We mated $\mathrm{VEGF}^{\mathrm{f} / \mathrm{fl}}\left(\mathrm{CRE}^{-}\right)$mice with RIP-CRE:VEGF ${ }^{\mathrm{fl} / \mathrm{fl}}$ mice to obtain RIP-CRE: $\mathrm{VEGF}^{\mathrm{fl} / \mathrm{fl}}$ mice in the next generation. In parallel, we mated RIP-CRE mice with wild-type C57BL/6J to obtain RIP-CRE mice in the next generation. All mice used in this study were backcrossed to C57BL/6J for a minimum of nine generations prior to the initiation of the crosses to generate the compound transgenic/knock-out mice. Genomic PCR analysis for determination of genotype was performed as described previously [6]. 
Immunohistochemical analysis After anaesthetisation of 20-week-old mice, the pancreas was removed after heart perfusion, and fixed in a solution of $4 \%$ paraformaldehyde or zinc formalin at $4{ }^{\circ} \mathrm{C}$ overnight. The fixed tissue was embedded in paraffin and mounted on slides. Immunohistochemical analysis was carried out using antibodies for insulin (Linco Research, St Charles, MO, USA; dilution 1:200), glucagon (Linco; dilution 1:200) and CD31 (Pharmingen, San Diego, CA, USA; dilution 1:200) as described previously [16]. The percentage of area immunopositive for CD31 and glucagon, as well as islet beta cell area were determined on CD31-, glucagon-, and insulin-stained sections captured with a microscope (E800; Nikon, Tokyo, Japan) connected to an XYZ controller and digital camera (Sony, Tokyo, Japan). Each area was determined on ten immunostained sections from five mice each, with each section separated by at least $200 \mu \mathrm{m}$. The areas of positive staining were automatically measured using an image analysis software (Image Pro4.5J; Planetron, Tokyo, Japan). Non-specific staining was excluded from the quantification. The percentage areas immunopositive for CD31 and glucagon represented the respective immunopositive area relative to the whole islet area. The percentage of beta cell area was calculated by the following formula: islet beta cell area $(\%)=$ the area stained by insulin antibody/the area of the whole pancreatic area.

Electron microscopy Each mouse (20-week-old) was anaesthetised with pentobarbital sodium and the pancreas was removed after heart perfusion and fixed in a solution of $2.5 \%$ glutaraldehyde. The pancreas was cut into pieces of approximately $1 \mathrm{~mm}^{3}$. When using the isolated islets as samples, the islets were fixed in a solution of $2.5 \%$ glutaraldehyde soon after isolation. The samples were fixed for $2 \mathrm{~h}$ in $2.5 \%$ glutaraldehyde buffered to $\mathrm{pH} 7.4$ with phosphate buffer, and treated with osmium tetroxide for $2 \mathrm{~h}$ at $4{ }^{\circ} \mathrm{C}$. The tissues were dehydrated with graded concen- tration ethanol, and then embedded in Epon 812 (TAAB Laboratories, Reading, Berks, UK). Thin sections were cut with a Leica Ultracut UCT (Leica Microsystems, Tokyo, Japan) with a diamond knife and stained with uranyl acetate followed by lead citrate [17]. Electron micrographs were taken with a JEOL JEM-1200EX electron microscope (JEOL, Tokyo, Japan) operated at $80 \mathrm{kV}$. Using images of electron micrographs, we measured the area of insulincontaining granules in three single beta cells from five mice in each group using an image analysis software (Image Pro4.5J).

Measurement of blood glucose and insulin concentrations in vivo For details on methods, see Electronic supplementary material (ESM).

Assay of insulin secretion from isolated islets and islet insulin content Pancreatic islets were isolated from 12week-old mice by collagenase digestion as described previously [18]. The islets were pre-incubated for $30 \mathrm{~min}$ in Krebs-Ringer solution (KRS) at $37^{\circ} \mathrm{C}$ with $5 \% \mathrm{CO}_{2}$ and saturated humidity. Size-matched islets $(n=10)$ were incubated in $400 \mu \mathrm{l}$ KRS containing various insulinotrophic agents for $30 \mathrm{~min}$ at $37^{\circ} \mathrm{C}$. At the end of incubation, aliquots of the buffer were immediately sampled and all samples were kept at $-80^{\circ} \mathrm{C}$ until assay. For measurement of islet insulin content, islets were solubilised in acidethanol solution overnight at $4^{\circ} \mathrm{C}$. Insulin concentration was analysed by RIA kit (Linco). Islet insulin concentration was corrected by DNA contents.

Islet perifusion The kinetics of insulin release was studied in vitro using a perifusion system. Pancreatic islets were isolated as mentioned above and used freshly after isolation. Size-matched islets $(n=50)$ were placed in each column. Then the columns were gently closed with the top adaptors, immersed in a vertical position in a temperaturecontrolled water bath at $37^{\circ} \mathrm{C}$. The perifusion medium was

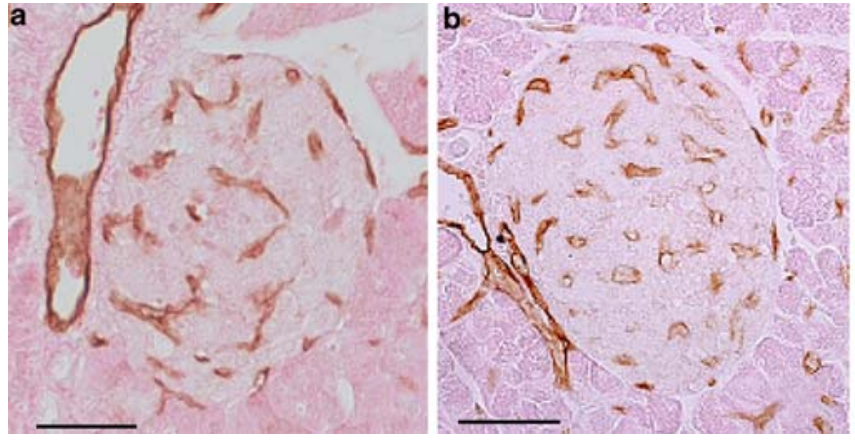

Fig. 1 Endothelial cell density in RIP-CRE:VEGF ${ }^{\mathrm{fl} / \mathrm{fl}}$ islets. Typical immunohistochemical staining for CD31 in RIP-CRE (a), VEGF ${ }^{\mathrm{fl}}$ ${ }^{\mathrm{fl}}\left(\mathrm{CRE}^{-}\right)$(b) and RIP-CRE:VEGF ${ }^{\mathrm{fl} / \mathrm{fl}}$ mice (c). Scale bars $=100 \mu \mathrm{m}$. d Percentages of CD31-immunopositive areas $(n=5$ each) in islets from
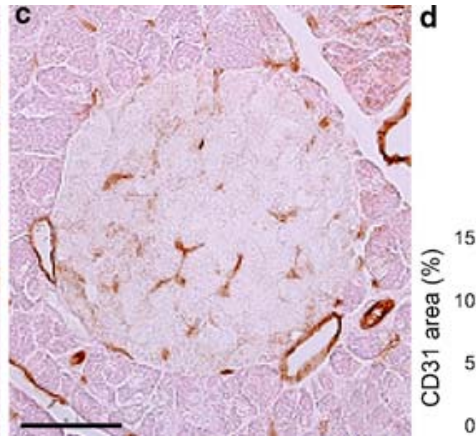

RIP-CRE (open bar), $\mathrm{VEGF}^{\mathrm{fl} / \mathrm{fl}}\left(\mathrm{CRE}^{-}\right.$) (hatched bar) and RIP-CRE: $\mathrm{VEGF}^{\mathrm{fl} / \mathrm{fl}}$ (filled bar) mice. Data are mean \pm SEM. ${ }^{*} p<0.05$ vs RIP$\mathrm{CRE} ;{ }^{* *} p<0.05$ vs $\mathrm{VEGF}^{\mathrm{fl} / \mathrm{fl}}\left(\mathrm{CRE}^{-}\right)$mice 
maintained at $37^{\circ} \mathrm{C}$ in a water-bath. All columns were perifused in parallel at a flow rate of $0.5 \mathrm{ml} / \mathrm{min}$ with $\mathrm{KRS}$ $(2.8 \mathrm{mmol} / \mathrm{l}$ glucose $)$ and at $37^{\circ} \mathrm{C}$. After $60 \mathrm{~min}$ of static incubation with KRS $(2.8 \mathrm{mmol} / 1$ glucose $)$, the islets were stimulated by the continuous presence of $16.7 \mathrm{mmol} / 1$ glucose. Samples were collected every $20 \mathrm{~s}$ until $2 \mathrm{~min}$, every $1 \mathrm{~min}$ until $5 \mathrm{~min}$, and thereafter every $5 \mathrm{~min}$ until $30 \mathrm{~min}$ [19]. Samples were immediately stored at $-80^{\circ} \mathrm{C}$ until further analysis. Insulin concentration was measured with an insulin RIA kit (Linco).

Tissue RNA isolation and real-time quantitative $R T$ $P C R$ Total RNA was isolated from approximately 200 islets using the TRIzol reagent (Invitrogen, Carlsbad, CA, USA) and first-strand cDNA was synthesised using $3 \mu \mathrm{g}$ of total RNA with OligodT primers and superscript reverse transcriptase (Invitrogen). For the quantitative SYBR Green real-time PCR, cDNA was analysed with a PCR instrument (ABI 7700; Applied Biosystems, Foster City, CA, USA) and $2 \times$ SYBR Green PCR Master Mix (Applied Biosystems) and specific primers. Thermal cycles for amplification were set as follows: $2 \mathrm{~min}$ at $50^{\circ} \mathrm{C}, 10 \mathrm{~min}$ at $95^{\circ} \mathrm{C}$ and 40 cycles of $95^{\circ} \mathrm{C}$ for $45 \mathrm{~s}, 60^{\circ} \mathrm{C}$ for $45 \mathrm{~s}$, and $72^{\circ} \mathrm{C}$ for $45 \mathrm{~s}$. By this protocol, neither non-specific primer-dimer amplification, nor PCR products were observed in no-template control samples. Single band PCR products were detected by $1 \%$ agarose gels with end-reaction products. The relative expression levels of mRNAs were calculated by the cycle threshold method with standard cDNA. We used $\beta$-actin mRNA as the internal invariant standard. The primers used in this study are listed in ESM Table 1.

Statistical analysis Results are expressed as mean \pm SEM. The unpaired Student's $t$ test was used to compare the laboratory data of two groups. When comparisons of more than three groups were required, statistical significance was determined by one-way ANOVA and Scheffe's method as a post hoc test. $p<0.05$ was considered significant.

\section{Results}

Morphology of islets in RIP-CRE:VEGF fl/fl mice Recently, Lee et al. [20] reported that RIP-CRE mice showed glucose intolerance with impaired insulin secretion. Thus, we used both RIP-CRE mice and VEGF $^{\mathrm{fl} / \mathrm{fl}}$ mice as controls in this study. As we described previously [6], RIP-CRE:VEGF ${ }^{\mathrm{fl} / \mathrm{fl}}$ mice showed a remarkable reduction of immunoreactivity of VEGFA in islets. Quantification of the area positive for CD31 revealed a marked reduction of islet endothelial cells in RIP-CRE:VEGF ${ }^{\mathrm{fl} / \mathrm{fl}}$ mice compared with RIP-CRE and $V_{E G F} F^{f / f l}$ mice (Fig. 1). To further investigate the structural change in endothelial cells in islets of RIP-CRE:VEGF ${ }^{\mathrm{fl} / \mathrm{fl}}$ mice, we examined endothelial morphology of islets by means of electron microscopy. Thin fenestrated endothelial cells were observed in the control $\mathrm{VEGF}^{\mathrm{fl} / \mathrm{fl}}\left(\mathrm{CRE}^{-}\right)$mice (Fig. 2a,c,e) and RIP-CRE mice (data not shown). On the other hand, extensive changes were observed in endothelial cells in islets from RIP-CRE:VEGF ${ }^{\mathrm{fl} / \mathrm{fl}}$ mice, these changes being characterised by little fenestration and increased caveolae-like structures (Fig. 2b,d,f). In addition, the
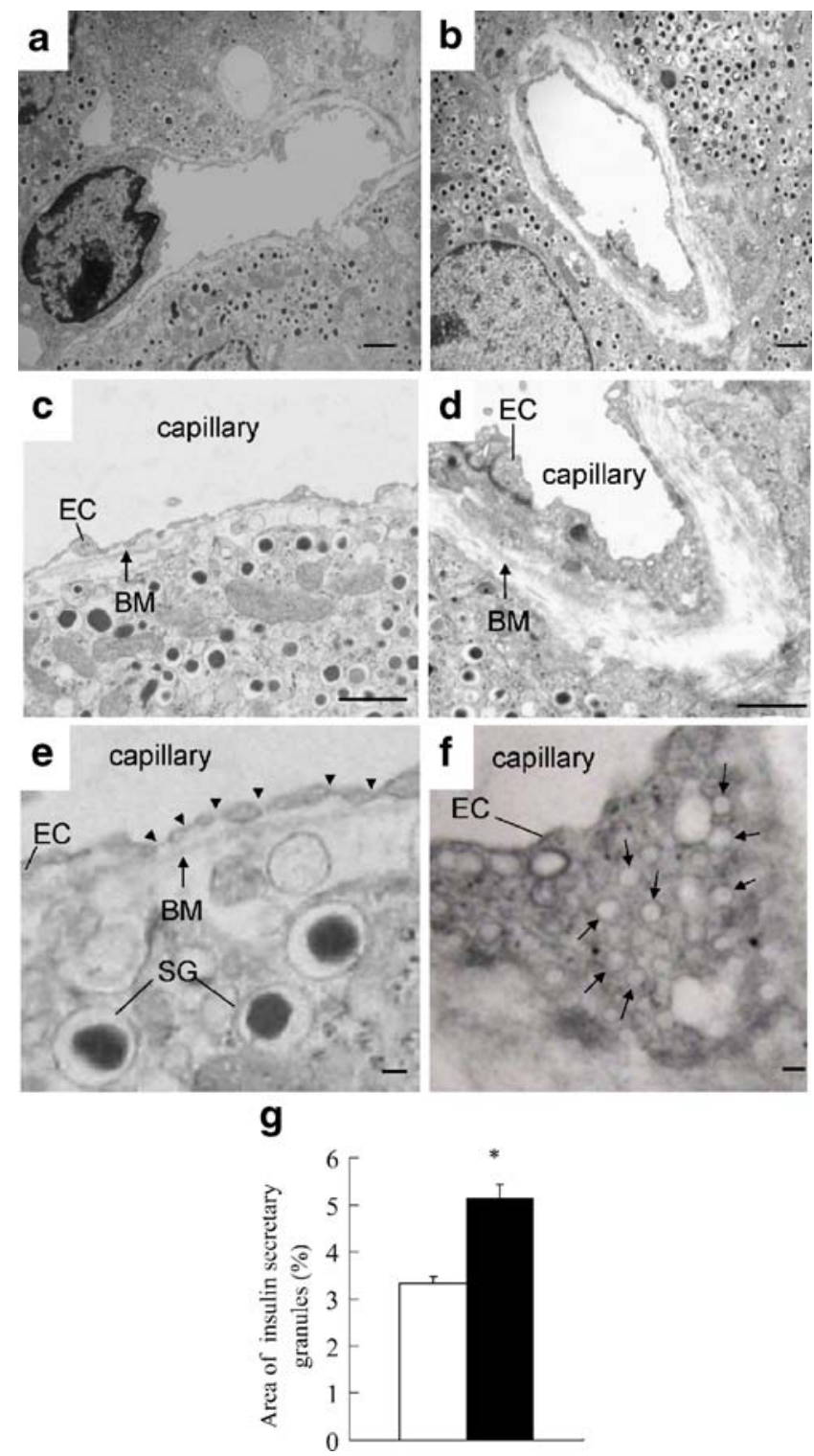

Fig. 2 Vascular structure of islets of $\mathrm{VEGF}^{\mathrm{fl} / \mathrm{fl}}\left(\mathrm{CRE}^{-}\right)$and RIP-CRE: $\mathrm{VEGF}^{\mathrm{fl} / \mathrm{fl}}$ mice. Electron microscopy showing capillaries surrounded by pancreatic beta cells in $\mathrm{VEGF}^{\mathrm{fl} / \mathrm{fl}}\left(\mathrm{CRE}^{-}\right)(\mathbf{a}, \mathbf{c}, \mathbf{e})$ and RIP-CRE: $\operatorname{VEGF}^{\mathrm{fl} / \mathrm{fl}}$ mice $(\mathbf{b}, \mathbf{d}, \mathbf{f})$. Scale bars $=0.25 \mu \mathrm{m}(\mathbf{a}-\mathbf{d})$ and $50 \mathrm{~nm}(\mathbf{e}, \mathbf{f})$. Arrowheads point to fenestrate (e), arrows (f) point to caveolae-like structures. $E C$, endothelial cell; $S G$, secretory granule; $B M$, basement membrane. Magnification: $\times 1,000(\mathbf{a}, \mathbf{b}) ; \times 3,000(\mathbf{c}, \mathbf{d}) ; \times 10,000(\mathbf{e}$, f). $\mathbf{g}$ Percentage area of insulin-containing granules $(n=5$ each) in islets of $\operatorname{VEGF}^{\mathrm{fl} / \mathrm{fl}}\left(\mathrm{CRE}^{-}\right)$(open bar) and RIP-CRE:VEGF ${ }^{\mathrm{fl} / \mathrm{fl}}$ mice (filled bar). Data are mean \pm SEM. ${ }^{*} p<0.05$ vs RIP-CRE mice 
basement membrane separating endothelial cells from endocrine cells was thicker in RIP-CRE:VEGF ${ }^{\mathrm{fl} / \mathrm{fl}}$ mice than in control mice. Normal fenestrated endothelial cells were occasionally observed in islets of RIP-CRE:VEGF $F^{\mathrm{fl} / \mathrm{fl}}$ mice, probably due to residual VEGFA production in beta cells. These morphological changes in endothelial cells are similar to those reported in PDX1-CRE:VEGF ${ }^{\mathrm{fl} / \mathrm{fl}}$ mice [10], thus confirming that expression of the gene encoding VEGFA in insulin-producing cells is important for maintaining the normal morphology of the microvascular structure in islets. In contrast to the observation in PDX1-CRE: $\mathrm{VEGF}^{\mathrm{fl} / \mathrm{fl}}$ mice, quantification of the area of insulin-containing granules in single beta cells demonstrated that the density of insulin-containing granules in RIP-CRE: VEGF ${ }^{\mathrm{fl} / \mathrm{fl}}$ beta cells was increased compared with control mice (Fig. 2g). The amount and distribution of alpha cells in islets was not altered in RIP-CRE:VEGF ${ }^{\mathrm{fl} / \mathrm{fl}}$ mice (Fig. 3a-d). Quantitative morphometry showed that the islet beta cell mass in RIPCRE:VEGF ${ }^{\mathrm{fl} / \mathrm{fl}}$ pancreas was comparable with that in RIP$\mathrm{CRE}$ and $\operatorname{VEGF}^{\mathrm{fl} / \mathrm{fl}}\left(\mathrm{CRE}^{-}\right)$pancreas (Fig. 3e-h). Thus, apart from the abnormality of islet endothelial cells, we did not find any obvious morphological abnormality in islets of RIP-CRE:VEGF ${ }^{\mathrm{fl} / \mathrm{fl}}$ mice.

Impaired insulin and glucagon secretion in RIP-CRE: $V E G F^{f l / f l}$ mice The body weight of RIP-CRE:VEGF $F^{\mathrm{fl} / \mathrm{fl}}$ mice was comparable with that of RIP-CRE mice and VEGF $^{\mathrm{fl} / \mathrm{fl}}$ mice (data not shown). While fasting glucose levels were comparable among the groups (Fig. 4a,b), an intraperitoneal glucose challenge test identified glucose intolerance with impaired glucose-stimulated insulin secretion in RIP-CRE:VEGF ${ }^{\mathrm{fl} / \mathrm{fl}}$ mice (Fig. 4a-d). Glucose intolerance was persistently observed from 8 to 20 weeks of age (Fig. 4a,b, and data not shown). A slight deterioration of glucose tolerance was observed with ageing, although no apparent decrease in insulin secretion was noted. It is probable that the ageing-related worsening of glucose tolerance was due to an ageing-related increase in insulin resistance. In addition, glucose tolerance and glucose-stimulated insulin secretion were also comparable in RIP-CRE and $\mathrm{VEGF}^{\mathrm{fl} / \mathrm{fl}}$ mice. Thus, our results indicate that not the expression of Cre, but the deletion of Vegfa in beta cells impairs the rapid insulin release induced by increased glucose levels in the RIP-CRE:VEGF ${ }^{\mathrm{fl} / \mathrm{fl}}$ mice. RIP-CRE:VEGF ${ }^{\mathrm{fl} / \mathrm{fl}}$ mice also showed a decrease in tolbutamide-stimulated insulin secretion and arginine-stimulated glucagon secretion (Fig. $4 \mathrm{e}-\mathrm{h}$ ). These results suggest that deletion of Vegfa in beta cells results in impaired hormone release from islets.

Increased insulin secretion in isolated islets in RIP-CRE: $V E G F^{f l f l}$ mice To elucidate whether the impaired insulin secretion observed in RIP-CRE:VEGF ${ }^{\mathrm{fl} / \mathrm{fl}}$ mice was caused by impaired beta cell function, we investigated glucosestimulated insulin secretion using isolated islets. First, we compared ultrastructural changes in isolated $\mathrm{VEGF}^{\mathrm{fl} / \mathrm{fl}}$
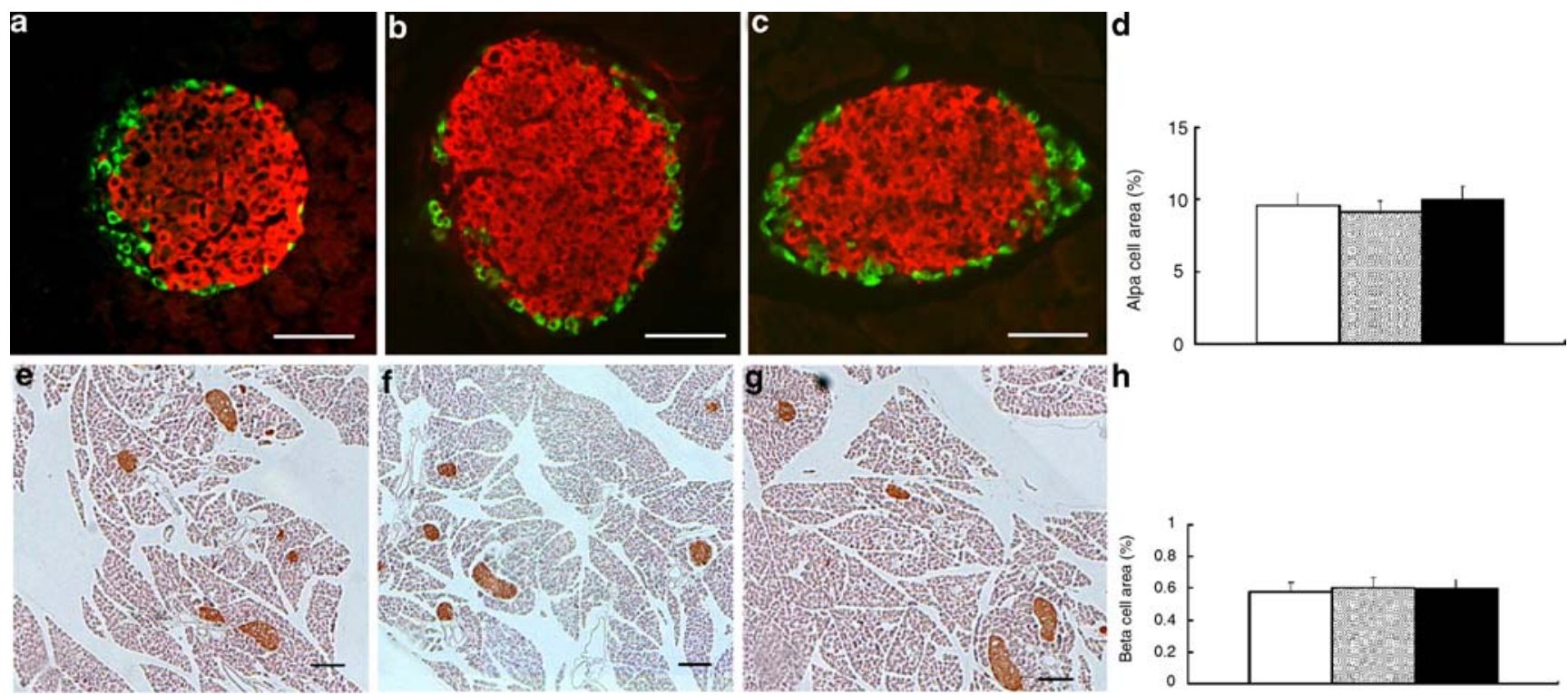

Fig. 3 Morphology of islets of RIP-CRE, VEGF ${ }^{\mathrm{fl} / \mathrm{fl}}\left(\mathrm{CRE}^{-}\right)$and RIP$\mathrm{CRE}: \mathrm{VEGF}^{\mathrm{fl} / \mathrm{fl}}$ mice. Typical immunofluorescence double staining for insulin and glucagon in RIP-CRE (a), VEGF ${ }^{\mathrm{fl} / \mathrm{fl}}\left(\mathrm{CRE}^{-}\right)$(b) and RIPCRE: $\operatorname{VEGF}^{\mathrm{f} / \mathrm{fl}}$ (c) mice. Scale bars $=100 \mu \mathrm{m}$. d Percentage of area immunopositive for glucagons in islets of RIP-CRE (open bar), $\mathrm{VEGF}^{\mathrm{fl} / \mathrm{fl}}\left(\mathrm{CRE}^{-}\right)$(hatched bar) and RIP-CRE:VEGF ${ }^{\mathrm{fl} / \mathrm{fl}}$ mice (filled

bar) ( $n=5$ each). e-g Typical immunostaining for insulin in RIPCRE (e), VEGF ${ }^{\mathrm{fl} / \mathrm{fl}}\left(\mathrm{CRE}^{-}\right)$(f) and RIP-CRE:VEGF ${ }^{\mathrm{fl} / \mathrm{fl}}(\mathbf{g})$ mice. Scale bars $=100 \mu \mathrm{m}$. h Beta cell area (\%) in islets of RIP-CRE (open bar), $\mathrm{VEGF}^{\mathrm{fl} / \mathrm{fl}}\left(\mathrm{CRE}^{-}\right)$(hatched bar) and RIP-CRE:VEGF ${ }^{\mathrm{fl} / \mathrm{fl}}$ (filled bar) mice $(n=5$ each). Data are mean \pm SEM 
(CRE ${ }^{-}$) and RIP-CRE:VEGF ${ }^{\mathrm{fl} / \mathrm{fl}}$ islets, but using electron microscopic observation, we did not find any obvious ultrastructural changes in beta cells between $\mathrm{VEGF}^{\mathrm{fl} / \mathrm{fl}}$ $\left(\mathrm{CRE}^{-}\right)$and RIP-CRE:VEGF ${ }^{\mathrm{fl} / \mathrm{fl}}$ islets. As observed in pancreatic sections, the increase in insulin-containing granules in RIP-CRE:VEGF ${ }^{\mathrm{fl} / \mathrm{fl}}$ beta cells remained higher than
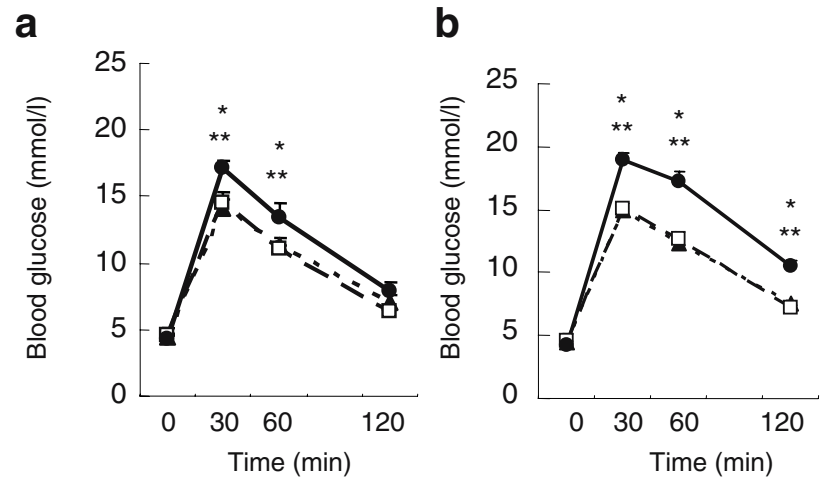

C
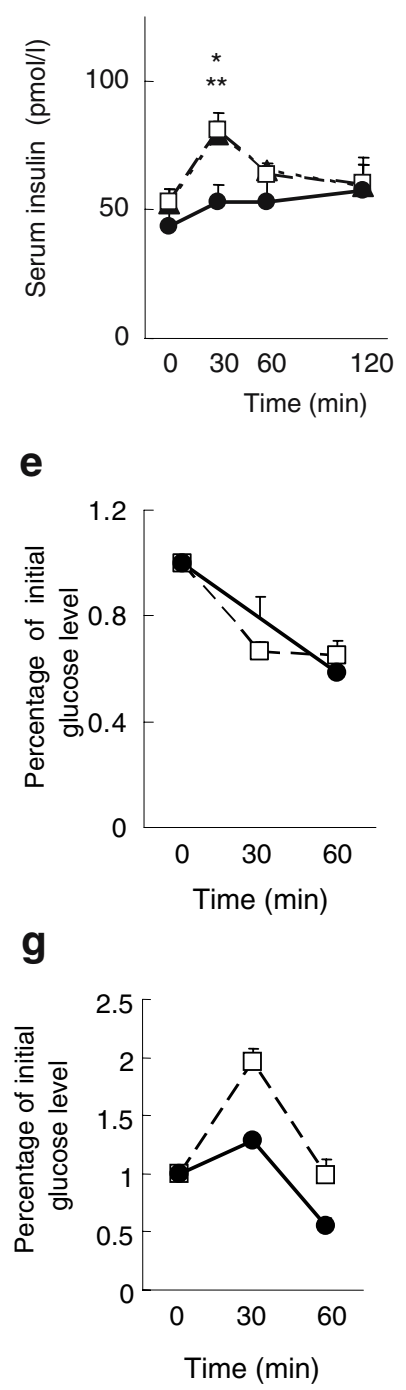

d

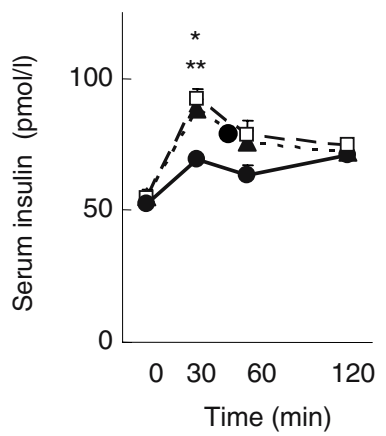

f

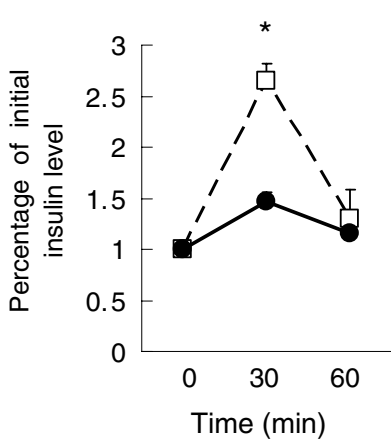

h

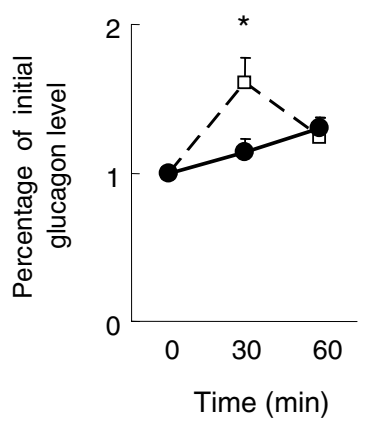

in control mice (ESM Fig. 1). According to a previous study [21], most endothelial cells remain in islets in the period soon after the isolation procedures. However, very few residual endothelial cells and several openings in the intercellular space were observed in both $\operatorname{VEGF}^{\mathrm{fl} / \mathrm{fl}}\left(\mathrm{CRE}^{-}\right)$ and RIP-CRE:VEGF ${ }^{\mathrm{fl} / \mathrm{fl}}$ islets (ESM Fig. 1). Because insulin secretagogues can directly infiltrate beta cells, at least in this condition, it is possible to investigate islet function after eliminating the major influence of endothelial cell dysfunction. In contrast to beta cell function in RIP-CRE:VEGF ${ }^{\mathrm{f} / \mathrm{fl}}$ mice in vivo, glucose- and $\mathrm{KCl}$-stimulated levels of secreted insulin from isolated islets of RIP-CRE:VEGF ${ }^{\mathrm{fl} / \mathrm{fl}}$ mice were not lower, but instead higher than from RIP-CRE and $\operatorname{VEGF}^{\mathrm{fl} / \mathrm{fl}}\left(\mathrm{CRE}^{-}\right)$islets (Fig. 5a). Islet perifusion studies also revealed that the rapid insulin secretion of RIP-CRE:VEGF ${ }^{\mathrm{fl} / \mathrm{fl}}$ islets was higher than RIP-CRE, and $\mathrm{VEGF}^{\mathrm{fl} / \mathrm{fl}}\left(\mathrm{CRE}^{-}\right)$mice (Fig. 5b). To further investigate the mechanism of increased insulin secretion in RIP-CRE:VEGF ${ }^{\mathrm{fl} / \mathrm{fl}}$ islets, we quantitated insulin content and mRNA of RIP-CRE:VEGF ${ }^{\mathrm{fl} / \mathrm{fl}}$ islets. Insulin content and insulin I (InsI) mRNA in RIP-CRE: $\mathrm{VEGF}^{\mathrm{fl} / \mathrm{fl}}$ islets was higher than in control islets (Fig. 6).

Previous data have demonstrated that several transcription factors orchestrate the expression of insulin gene [22]. Of these, PDX1 is one of the most important. Thus, we quantitated the expression level of $P d x 1$ mRNA in RIPCRE, and $\mathrm{VEGF}^{\mathrm{fl} / \mathrm{fl}}\left(\mathrm{CRE}^{-}\right)$mice. We found that RIP-CRE: VEGF $^{\mathrm{fl} / \mathrm{fl}}$ islets express higher levels of $P d x 1$ mRNA than control islets. In addition, because RIP-CRE:VEGF ${ }^{\mathrm{fl} / \mathrm{fl}}$ islets contain more insulin-containing granules and secrete more insulin than control mice in vitro, we investigated whether the morphological increase in insulin granules accompanies the increase in essential components of exocytosis. Soluble $\mathrm{N}$-ethylmaleimide-sensitive factor attachment protein receptors (SNARE) and its related proteins are among these components. As shown in Fig. 6, RIP-CRE:VEGF ${ }^{\mathrm{fl} / \mathrm{fl}}$ islets

Fig. 4 Impaired glucose tolerance with impaired insulin secretion in vivo in RIP-CRE, VEGF ${ }^{\mathrm{f} / \mathrm{fl}}\left(\mathrm{CRE}^{-}\right)$and RIP-CRE:VEGF ${ }^{\mathrm{fl} / \mathrm{fl}}$ mice. Blood glucose concentrations during intraperitoneal glucose tolerance tests in 8-week-old (a) and 20-week-old (b) RIP-CRE (filled triangles), $\mathrm{VEGF}^{\mathrm{fl} / \mathrm{fl}}\left(\mathrm{CRE}^{-}\right)$(blank squares) and RIP-CRE:VEGF ${ }^{\mathrm{fl} / \mathrm{fl}}$ (filled circles) mice. Serum insulin concentrations during intraperitoneal glucose tolerance tests in 8-week-old (c) and 20-week-old (d) RIP-CRE (filled triangles), $\mathrm{VEGF}^{\mathrm{fl} / \mathrm{fl}}\left(\mathrm{CRE}^{-}\right)$(blank squares), and RIP-CRE:VEGF ${ }^{\mathrm{fl} / \mathrm{fl}}$ (filled circles) mice. Blood glucose (e) and serum insulin (f) concentrations during intraperitoneal tolbutamide tolerance tests in $\mathrm{VEGF}^{\mathrm{fl} / \mathrm{fl}}\left(\mathrm{CRE}^{-}\right)$(blank squares) and RIP-CRE:VEGF ${ }^{\mathrm{fl} / \mathrm{fl}}$ (filled circles) mice. $\mathbf{g}$, h Blood glucose and glucagon concentrations, respectively, during intraperitoneal arginine tolerance tests in $\mathrm{VEGF}^{\mathrm{fl} / \mathrm{fl}}$ $\left(\mathrm{CRE}^{-}\right)$(blank squares) and RIP-CRE:VEGF ${ }^{\mathrm{fl} / \mathrm{fl}}$ (filled circles) mice. Tolbutamide and arginine tolerance tests were conducted in 12-weekold mice and are represented as percentage of initial values. Data are mean \pm SEM (RIP-CRE, $n=7$; VEGF ${ }^{\mathrm{fl} / \mathrm{fl}}\left(\mathrm{CRE}^{-}\right), n=10$; RIP-CRE: $\left.\mathrm{VEGF}^{\mathrm{fl} / \mathrm{fl}}, n=10\right) *{ }^{*}<0.05$ vs RIP-CRE; $* * p<0.05 \operatorname{vsVEGF}^{\mathrm{fl} / \mathrm{fl}}\left(\mathrm{CRE}^{-}\right)$ mice 
a

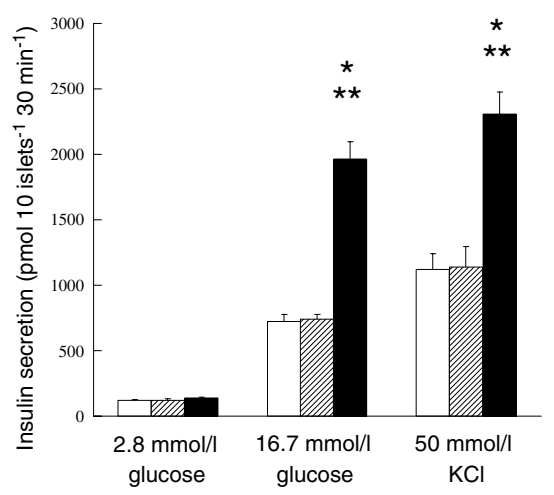

b

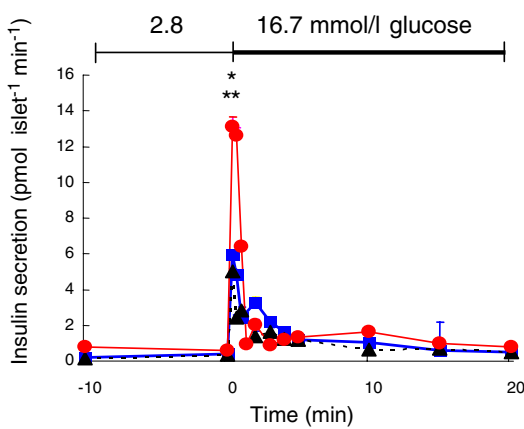

Fig. 5 Insulin release in isolated islets in RIP-CRE, VEGF ${ }^{\mathrm{fl} / \mathrm{fl}}\left(\mathrm{CRE}^{-}\right)$ and RIP-CRE:VEGF ${ }^{\mathrm{fl} / \mathrm{fl}}$ mice. a Glucose- and $\mathrm{KCl}$-induced insulin secretion was investigated by using batch-incubated islets of RIP-CRE (open bars), $\mathrm{VEGF}^{\mathrm{fl} / \mathrm{fl}}\left(\mathrm{CRE}^{-}\right.$) (hatched bars) and RIP-CRE:VEGF ${ }^{\mathrm{f} / \mathrm{fl}}$ (filled bars) mice. Data are mean \pm SEM ( $n=7-10$ mice). b Glucoseinduced insulin release was assessed by islet perifusion experiments. We isolated 50 islets each from RIP-CRE (filled triangles), $\mathrm{VEGF}^{\mathrm{fl} / \mathrm{fl}}$ $\left(\mathrm{CRE}^{-}\right)$(blue squares) and RIP-CRE:VEGF ${ }^{\mathrm{fl} / \mathrm{fl}}$ (red circles) mice for use in the experiments. Data are mean $\pm \operatorname{SEM}\left(n=5\right.$ each). ${ }^{*} p<0.05$ vs RIP-CRE, $* * p<0.05$ vs VEGF $^{\mathrm{fl} / \mathrm{fl}}\left(\mathrm{CRE}^{-}\right)$

express higher levels of the genes encoding SNARE and its related proteins. Thus, it is likely that the increase in insulin secretion in RIP-CRE:VEGF ${ }^{\mathrm{fl} / \mathrm{fl}}$ islets is simply due to an increase in the releasable pool of insulin granules that comes with an increase in Ins1 mRNA.

\section{Discussion}

In this study, we investigated the role of VEGFA on beta cell function using RIP-CRE:VEGF ${ }^{\mathrm{fl} / \mathrm{fl}}$ mice, in which Vegfa has been disrupted specifically in beta cells. Our major findings are that RIP-CRE:VEGF ${ }^{\mathrm{f} / \mathrm{fl}}$ mice exhibited impaired glucose tolerance with reduced rapid insulin release, whereas isolated islets of RIP-CRE:VEGF ${ }^{\mathrm{fl} / \mathrm{fl}}$ have greater insulin content and show higher insulin secretion. Thus, the

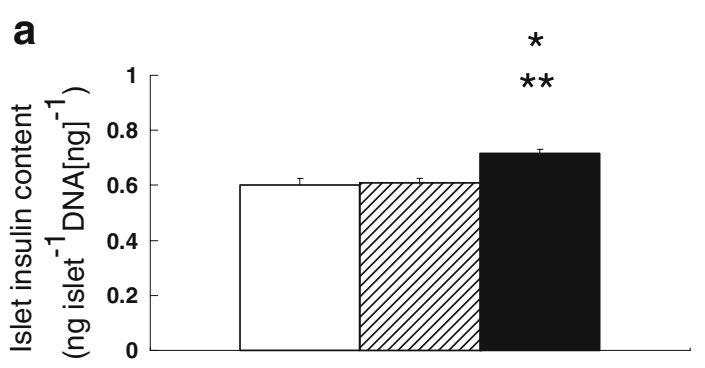

b

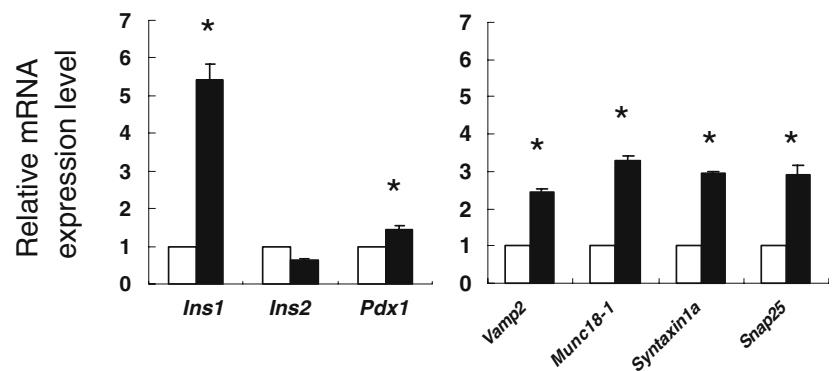

Fig. 6 Insulin content and relative mRNA expression in RIP-CRE: VEGF $^{\mathrm{fl} / \mathrm{fl}}$ islets. a Insulin content of isolated islets of RIP-CRE (open bar), $\operatorname{VEGF}^{\mathrm{fl} / \mathrm{fl}}\left(\mathrm{CRE}^{-}\right)$(hatched bar) and RIP-CRE:VEGF ${ }^{\mathrm{fl} / \mathrm{fl}}$ (filled bar) mice ( $n=5$ each). ${ }^{*} p<0.05$ vs RIP-CRE mice; $* * p<0.05$ vs $\mathrm{VEGF}^{\mathrm{fl} / \mathrm{fl}}\left(\mathrm{CRE}^{-}\right)$mice. $\mathbf{b}$ Relative mRNA expression was measured by real-time RT-PCR analysis, and expressed in RIP-CRE:VEGF ${ }^{\mathrm{fl} / \mathrm{fl}}$ islets as values relative to $\operatorname{VEGF}^{\mathrm{fl} / \mathrm{fl}}\left(\mathrm{CRE}^{-}\right)$mice. ${ }^{*} p<0.05$ vs $\mathrm{VEGF}^{\mathrm{fl} / \mathrm{fl}}$ $\left(\mathrm{CRE}^{-}\right)$mice. Data are mean $\pm \mathrm{SEM}(n=5)$. Ins 1, Ins2, insulin I and II, respectively; $P d x 1$, pancreas duodenum hoemobox 1; Vamp2, vesicular-associated membrane protein 2; Munc18-1, mammalian homologue of the unc-18; Snap25, synaptosomal associated protein of $25 \mathrm{kDa}$

impaired formation of endothelial cells in islets is involved in the impaired glucose-stimulated insulin secretion.

Previous reports have indicated that VEGFA plays an essential role in the maintenance of endothelial cell number and formation of endothelial fenestration [8, 23]. PDX1CRE:VEGF ${ }^{\mathrm{fl} / \mathrm{fl}}$ mice [10] have few endothelial cells, reduced fenestrate and increased caveolae in residual islet endothelial cells. As shown in the present study, RIP-CRE: $\mathrm{VEGF}^{\mathrm{fl} / \mathrm{fl}}$ mice showed similar morphological changes in islet endothelial cells. The main difference, however, was that the islets of these mice showed an increased number of insulin-containing granules, although it has been reported that PDX1-CRE: VEGF ${ }^{\mathrm{fl} / \mathrm{fl}}$ mice had a reduced number of insulin-containing granules in the islets [10]. PDX1 production occurs before formation of the pancreatic bud in pancreatic primordial tissue $[24,25]$. Theoretically, VEGFA is deleted in whole pancreatic epithelial-derived cells early in the development of the pancreas in PDX1$\mathrm{CRE}$ :VEGF ${ }^{\mathrm{fl} / \mathrm{fl}}$ mice. In contrast, in RIP-CRE:VEGF ${ }^{\mathrm{fl} / \mathrm{fl}}$ mice, VEGFA is deleted only in insulin-producing cells and the recombination event commences at a later stage of pancreatic development. Thus, we cannot rule out the possibility that the difference in phenotype might be based 
on the difference of timing and cells of the recombination event. Alternatively, this difference could result from the number of residual functional endothelial cells. Based on recent data, beta cells, in contrast to exocrine pancreatic cells, do not form a basement membrane [12]. Instead, endothelial cells form vascular basement membrane next to the beta cells in islets. Laminins, a vascular basement membrane protein, promote insulin gene expression and proliferation of beta cells [12]. Taking these findings into account, the residual amounts of endothelial cells seem to affect insulin contents. In fact, the relative reduction of endothelial cell area in the islets of PDX1-CRE:VEGF ${ }^{\mathrm{fl} / \mathrm{fl}}$ mice was reported to be $84 \%$. On the other hand, the relative reduction of endothelial cell area in the islets of RIP-CRE: VEGF ${ }^{\mathrm{fl} / \mathrm{fl}}$ mice was $60.5 \%$ (Fig. 1). If the threshold for the number of functional endothelial cells that results in reduced insulin content lies between that in PDX1-CRE:VEGF ${ }^{\mathrm{f} / \mathrm{fl}}$ mice and that in RIP-CRE:VEGF ${ }^{\mathrm{f} / \mathrm{fl}}$ mice, the difference in insulin content between these mice might be due to the number of residual endothelial cells. If so, the association between the number of endothelial cells and insulin content should not be linear. Clearly, further assessment is needed to complete our understanding of the impact of VEGFA in islets on insulin contents.

In RIP-CRE:VEGF ${ }^{\mathrm{fl} / \mathrm{fl}}$ mice, we found increases in the following: (1) expression of $P d x 1$, a transcription factor of insulin gene; (2) expression of Ins 1 mRNA; (3) insulin content in islets; (4) insulin granules in beta cells; and (5) the expression of genes encoding molecules implicated in regulated exocytosis, such as mammalian homologue of the unc-18, vesicular-associated membrane protein 2 , synaptosomal-associated protein of $25 \mathrm{kDa}$, and syntaxin-1A. These changes could be a cause of the hypersecretion of insulin observed in vitro and seemed to be a compensatory response for the decreased insulin secretion in vivo. However, according to recent work [5], both the decoy VEGF ligand and the small molecule VEGF receptor tyrosine kinase blocker can ameliorate glucose tolerance with decreased fasting glucose levels, without improving insulin sensitivity judged by an insulin tolerance test. In that study, no further information on the mechanism was provided. One possibility is that administration of the decoy VEGF ligand and the small molecule VEGF receptor tyrosine kinase blocker impaired the function of adrenal cortex or pituitary gland, which secrete counter-regulatory hormones through the decreased microvasculature structure. In fact, the authors [5] found increased serum thyroid stimulating hormone levels with decreased thyroid microvasculature as a result of treatment with VEGFA blockade. Thus, it is possible that the function of other endocrine organs might be impaired.

On the other hand, we cannot deny the possibility that VEGFA in beta cells somehow deteriorates beta cell function through an unknown mechanism. If so, the increased insulin content and insulin secretion observed in isolated islets of RIP-CRE:VEGF ${ }^{\mathrm{f} / \mathrm{fl}}$ mice was reasonable. In this case, in vivo phenotypical differences between RIP-CRE:VEGF ${ }^{\mathrm{fl} / \mathrm{fl}}$ mice and the administration of VEGFA inhibition might depend on the timing and periods of VEGFA blockade.

Apart from the direct effect via disturbed VEGFA signalling, recent data suggest that an autocrine effect of insulin through insulin receptor/phosphatidylinositol-3 kinase signalling pathways mediates beta cell function [26-30]. In RIP-CRE:VEGF ${ }^{\mathrm{fl} / \mathrm{fl}}$ mice, trans-endothelial passage of insulin might be impaired, possibly making the concentration of insulin around beta cells higher than in control mice. If so, in RIP-CRE:VEGF ${ }^{\mathrm{fl} / \mathrm{fl}}$ mice, the insulin signal should be enhanced. This might be one of the reasons for the higher insulin content in RIP-CRE:VEGF ${ }^{\mathrm{fl} / \mathrm{fl}}$ mice. Thus, from the above-mentioned possibilities, the increased insulin content and improved function of RIP-CRE:VEGF ${ }^{\mathrm{fl} / \mathrm{fl}}$ in vitro might not merely reflect a compensatory phenomenon in beta cells for impaired islet vascular function and impaired glucose tolerance in vivo.

The islet microvasculature network is thought to be important for both the quick sensing of blood glucose in beta cells and the rapid trans-endothelial passage of insulin. In the present study, insulin secretion stimulated by glucose and tolbutamide in RIP-CRE:VEGF ${ }^{\mathrm{fl} / \mathrm{fl}}$ mice was decreased. In addition, arginine-stimulated glucagon secretion was also decreased. Thus, although it is difficult to elucidate whether glucose sensing is impaired in RIP-CRE:VEGF ${ }^{\mathrm{fl} / \mathrm{fl}}$ mice, our data suggest that at least the permeability of substances from the blood stream and/or rapid trans-endothelial passage of hormones in islets was disturbed, and that this abnormality is involved in the abnormality of hormone secretion in these mice.

Recently, Lee et al. [20] reported that RIP-CRE mice suffer from impaired pancreatic beta cell function. In contrast to their report, our data revealed that glucose tolerance in RIP-CRE mice is comparable with that of $\mathrm{VEGF}^{\mathrm{fl} / \mathrm{fl}}$ mice. In addition, we found no differences regarding insulin secretion between RIP-CRE mice and $\mathrm{VEGF}^{\mathrm{fl} / \mathrm{fl}}$ mice. We do not know the exact reason for this discrepancy in this study. Because we set RIP-CRE mice as a control in most parts of the experiments, the phenotype observed in RIP-CRE:VEGF ${ }^{\mathrm{fl} / \mathrm{fl}}$ mice is not due to some toxic effect of the expression of $\mathrm{Cre}$ in beta cells.

RIP-CRE mice are known to show leaky production of CRE recombinase in the hypothalamus. Thus, we should take into account the effect of VEGFA in hypothalamus on the phenotype of RIP-CRE:VEGF ${ }^{\mathrm{fl} / \mathrm{fl}}$ mice. According to recent findings [5], the administration of VEGFA blockers decreased endothelial cells in islets, thyroid, small intestine villi, adrenal cortex, and choroid plexus, etc. On the other hand, the inhibition of VEGFA resulted in almost no effect 
on the microvasular structure in brain cortex and adrenal medulla. These findings suggest that the neural tissues contain very few VEGFA-dependent endothelial cells. Thus, VEGF deletion in hypothalamus rarely affects glucose tolerance.

Our data clearly suggest that disorganisation of islet vascularisation can impair glucose-stimulated insulin release, even if the function of beta cells is not impaired. We provide here evidence for the disorganisation of islet microcirculation as a mechanism of impaired insulin secretion. While adequate revascularisation is crucial for islet survival after transplantation, the vascular density in revascularised transplanted islets is markedly decreased [31]. In addition, previous data have demonstrated that the first phase of glucose-stimulated insulin release from islets transplanted to the liver was delayed, and less prominent when compared to that from the pancreas [32]. Considering islet function after transplantation, the decrease in islet vascular structure might be a main cause of decreased beta cell function. Our data clearly suggest that improved islet microvasculature could be a clue not only to islet survival, but also to maintaining normal islet function. In addition, our data suggest that the factors affecting islet endothelial cell formation could be a cause of the impaired glucosestimulated insulin secretion that is a typical feature of patients with type 2 diabetes.

Acknowledgements We thank M. Mitsumata (Department of Pathology, Nihon University School of Medicine, Tokyo, Japan) for helpful comments about the results of electron microscopy and immunohistochemistry, and E. Magoshi, Y. Toyofuku and N. Daimaru for their excellent technical assistance. This work was supported by grants from the Ministry of Education, Sports and Culture of Japan (to R. Kawamori) and the Suzuken Memorial Foundation (to H. Watada).

Duality of interest The authors declare that no duality of interest exists in the new findings of these studies.

\section{References}

1. Konstantinova I, Lammert E (2004) Microvascular development: learning from pancreatic islets. BioEssays 26:1069-1075

2. Henderson JR, Moss MC (1985) A morphometric study of the endocrine and exocrine capillaries of the pancreas. Q J Exp Physiol 70:347-356

3. Bonner-Weir S (1988) Morphological evidence for pancreatic polarity of beta-cell within islets of Langerhans. Diabetes 37:616-621

4. Orci L, Thorens B, Ravazzola M, Lodish HF (1989) Localization of the pancreatic beta cell glucose transporter to specific plasma membrane domains. Science 245:295-297

5. Kamba T, Tam BY, Hashizume H et al (2006) VEGF-dependent plasticity of fenestrated capillaries in the normal adult microvasculature. Am J Physiol Heart Circ Physiol 290:H560-H576

6. Inoue M, Hager JH, Ferrara N, Gerber HP, Hanahan D (2002) VEGF-A has a critical, nonredundant role in angiogenic switching and pancreatic beta cell carcinogenesis. Cancer Cell 1:193-202

7. Ferrara N, Gerber HP, LeCouter J (2003) The biology of VEGF and its receptors. Nat Med 9:669-676
8. Esser S, Wolburg K, Wolburg H, Breier G, Kurzchalia T, Risau W (1998) Vascular endothelial growth factor induces endothelial fenestrations in vitro. J Cell Biol 140:947-959

9. Issbrucker K, Marti HH, Hippenstiel S et al (2003) p38 MAP kinase - a molecular switch between VEGF-induced angiogenesis and vascular hyperpermeability. FASEB J 17:262-264

10. Lammert E, Gu G, McLaughlin M et al (2003) Role of VEGF-A in vascularization of pancreatic islets. Curr Biol 13:1070-1074

11. Shibuya M, Ito N, Claesson-Welsh L (1999) Structure and function of vascular endothelial growth factor receptor-1 and -2 . Curr Top Microbiol Immunol 237:59-83

12. Nikolova G, Jabs N, Konstantinova I et al (2006) The vascular basement membrane: a niche for insulin gene expression and beta cell proliferation. Dev Cell 10:397-405

13. Lammert E, Cleaver O, Melton D (2001) Induction of pancreatic differentiation by signals from blood vessels. Science 294:564-567

14. Postic C, Shiota M, Niswender KD et al (1999) Dual roles for glucokinase in glucose homeostasis as determined by liver and pancreatic beta cell-specific gene knock-outs using Cre recombinase. J Biol Chem 274:305-315

15. Gerber HP, Hillan KJ, Ryan AM et al (1999) VEGF is required for growth and survival in neonatal mice. Development 126:1149-1159

16. Choi JB, Uchino H, Azuma K et al (2003) Little evidence of transdifferentiation of bone marrow-derived cells into pancreatic beta cells. Diabetologia 46:1366-1374

17. Jeong KH, Rim HJ, Kim CW (1978) A study on the fine structure of Clonorchis sinensis, a liver fluke. 1. The body wall and the nervous system. Kisaengchunghak Chapchi 16:156-164 (article in Korean)

18. Nagamatsu S, Nakamichi Y, Yamamura C et al (1999) Decreased expression of t-SNARE, syntaxin 1 , and SNAP-25 in pancreatic beta-cells is involved in impaired insulin secretion from diabetic GK rat islets: restoration of decreased t-SNARE proteins improves impaired insulin secretion. Diabetes 48:2367-2373

19. Gorogawa S, Fujitani Y, Kaneto H et al (2004) Insulin secretory defects and impaired islet architecture in pancreatic beta-cellspecific STAT3 knockout mice. Biochem Biophys Res Commun 319:1159-1170

20. Lee JY, Ristow M, Lin X, White MF, Magnuson MA, Hennighausen L (2006) RIP-Cre revisited, evidence for impairments of pancreatic beta-cell function. J Biol Chem 281:2649-2653

21. Nyqvist D, Kohler M, Wahlstedt H, Berggren PO (2005) Donor islet endothelial cells participate in formation of functional vessels within pancreatic islet grafts. Diabetes 54:2287-2293

22. Melloul D, Marshak S, Cerasi E (2002) Regulation of insulin gene transcription. Diabetologia 45:309-326

23. Inai $T$, Mancuso $M$, Hashizume $H$ et al (2004) Inhibition of vascular endothelial growth factor (VEGF) signaling in cancer causes loss of endothelial fenestrations, regression of tumor vessels, and appearance of basement membrane ghosts. Am J Pathol 165:35-52

24. Ahlgren U, Jonsson J, Edlund H (1996) The morphogenesis of the pancreatic mesenchyme is uncoupled from that of the pancreatic epithelium in IPF1/PDX1-deficient mice. Development 122: 1409-1416

25. Offield MF, Jetton TL, Labosky PA et al (1996) PDX-1 is required for pancreatic outgrowth and differentiation of the rostral duodenum. Development 122:983-995

26. Kulkarni RN, Bruning JC, Winnay JN, Postic C, Magnuson MA, Kahn CR (1999) Tissue-specific knockout of the insulin receptor in pancreatic beta cells creates an insulin secretory defect similar to that in type 2 diabetes. Cell 96:329-339

27. Kido Y, Burks DJ, Withers D et al (2000) Tissue-specific insulin resistance in mice with mutations in the insulin receptor, IRS-1, and IRS-2. J Clin Invest 105:199-205

28. Withers DJ, Gutierrez JS, Towery H et al (1998) Disruption of IRS-2 causes type 2 diabetes in mice. Nature 391:900-904 
29. Bernal-Mizrachi E, Fatrai S, Johnson JD et al (2004) Defective insulin secretion and increased susceptibility to experimental diabetes are induced by reduced Akt activity in pancreatic islet beta cells. J Clin Invest 114:928-936

30. Uchida T, Nakamura T, Hashimoto N et al (2005) Deletion of $C d k n 1 b$ ameliorates hyperglycemia by maintaining compensatory hyperinsulinemia in diabetic mice. Nat Med 11:175-182
31. Mattsson G, Jansson L, Carlsson PO (2002) Decreased vascular density in mouse pancreatic islets after transplantation. Diabetes 51:1362-1366

32. Lau J, Jansson L, Carlsson PO (2006) Islets transplanted intraportally into the liver are stimulated to insulin and glucagon release exclusively through the hepatic artery. Am J Transplant 6:967-975 